\title{
An Elementary Overview of the Selection of Materials for Service in Oxygen- Enriched Environments
}

\begin{abstract}
:
The process for selecting materials for use in oxygen or oxygen-enriched environments is one that continues to be investigated by many industries due to the importance to those industries of oxygen systems. There are several excellent resources available to assist oxygen systems design engineers and end-users, with the most comprehensive being ASTM MNL-36, Safe Use of Oxygen and Oxygen Systems: Handbook for Design, Operation and Maintenance, $2^{\text {nd }}$ Edition. ASTM also makes available several standards for oxygen systems. However, the ASTM publications are extremely detailed, and typically designed for professionals who already possess a working knowledge of oxygen systems. No notable resource exists, whether an ASTM or other organizational publication, which can be used to educate engineers or technicians who have no prior knowledge of the nuances of oxygen system design and safety. This paper will fill the void for information needed by organizations that design or operate oxygen systems. The information in this paper is not new information, but is a concise and easily understood summary of selecting materials for oxygen systems. This paper will serve well as an employee's first introduction to oxygen system materials selection, and probably the employee's first introduction to ASTM.
\end{abstract}

\section{Introduction}

Oxygen is a highly reactive nonmetallic element that reacts with many other elements to form oxides through oxidation reactions. Oxygen comprises $20.9 \%$ of Earth's atmosphere and exists primarily in the form of $\mathrm{O}_{2}$ molecules. $\mathrm{O}_{2}$ is a pale blue odorless and tasteless gas which can also exist in a liquid state at temperatures below $-183^{\circ} \mathrm{C}\left(-297^{\circ} \mathrm{F}\right)$ and as a solid below $-219^{\circ} \mathrm{C}(-$ $362^{\circ} \mathrm{F}$ ). Oxygen in its liquid state is important because it provides a very large number of oxygen molecules per unit volume of containment. Liquid oxygen is easily stored, easily transferred from one tank to another, and is readily converted to gaseous oxygen.

The highly reactive nature of oxygen requires that special care must be taken when using it in order to ensure the safety of personnel and equipment. Materials that do not burn in normal atmosphere can burn violently, sometimes to the point of explosion, in oxygen. Also, liquid oxygen is very cold and can do severe damage to human skin on contact. Therefore, the use of oxygen, or oxygen-enriched medium, requires special safety precautions.

\section{Hazards Inherent in Oxygen-Enriched Environments}

The hazards inherent in oxygen systems arise primarily from the risk of fires. The standard fire triangle demonstrates that a fire requires three separate and independent components, represented as legs of the triangle. The three component legs are fuel, oxidizer and ignition source. The 
oxygen system obviously has the oxidizer leg, but what about a fuel leg? In an oxygen system, the hardware components actually can become the fuel!

Oxygen fires are mysterious and not well understood. Laboratory experiments with oxygen and materials have shown that oxygen fires are infrequent, even if the experimental conditions maximize the probably of a fire. Also, when fires are created in a laboratory setting, these fires are difficult to repeat. Oxygen fire hazards are very important to understand, however, because oxygen fire events are often catastrophic.

One special note - Oxygen-rich systems must always be treated as if they are pure oxygen systems. Many personnel injuries and deaths, and major equipment damage, have resulted from assuming that oxygen-rich systems can be treated as if they are air systems.

\section{Oxygen and Materials}

Oxygen is a powerful oxidizer, and as such, completes one leg of the fire triangle. See Figure 1. A fuel can be almost any material, even the system hardware, under the right conditions. Ignition sources are more common than most engineers believe. These three legs of the fire triangle can come together in the right circumstances to provide a very exothermic chemical reaction. The oxygen system designer must always remember that fires and explosions occur readily in oxygen systems, even when the systems are not under extreme conditions. In fact, all industries that use oxygen systems have experienced fires at one time or another. Many of these have resulted in a loss of life.

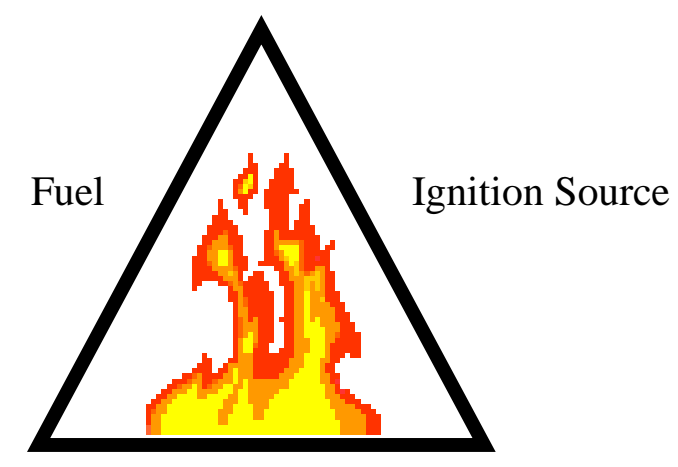

Oxidizer

Figure 1: The Fire Triangle

\section{Factors Significantly Influencing Combustion Probability and Severity for Materials in Oxygen Systems}

The ignition and combustion properties of materials are not the same from one oxygen system to another. Several factors determine ignition probability and fire severity. The three most important factors that significantly increase both the probability of ignition of a material and the 
severity of the fire once ignition has occurred are increasing oxygen concentration, increasing system pressure, and increasing system temperature.

\section{Oxygen Concentration Effects}

Combustible materials, with very few exceptions, burn far more readily and rapidly in environments that have higher concentrations of oxygen. The oxygen concentration within a system should be minimized to the lowest allowable. Table 1shows the affects of increasing oxygen concentrations on the fire hazards of materials.

\section{TABLE 1: Flammability of Nonmetals by Oxygen Concentration ${ }^{\mathrm{a}, \mathrm{b}, \mathrm{c}}$}

\begin{tabular}{|c|c|c|c|}
\hline Material & $\begin{array}{c}\text { Test Oxygen } \\
\text { Concentration }\end{array}$ & $\begin{array}{l}\text { 12” (305mm) length } \\
\text { x 2.5” (64mm) width } \\
\text { Sample Burn Length }\end{array}$ & $\begin{array}{c}\text { Burn Rate } \\
\text { inches/second } \\
\text { (mm/sec) }\end{array}$ \\
\hline \multirow[t]{2}{*}{ Polyester Based Foam } & $23 \%$ & $1.3 ”(33 \mathrm{~mm})$ & $0.07(1.8)$ \\
\hline & $25 \%$ & $12 ”(305 \mathrm{~mm})$ & $0.67(17.0)$ \\
\hline \multirow[t]{2}{*}{ Polyurethane and Epoxy } & $21 \%$ & $1 ”(25.4 \mathrm{~mm})$ & $0.05(1.3)$ \\
\hline & $26 \%$ & 12” (305 mm) & $0.33(8.4)$ \\
\hline \multirow[t]{2}{*}{ Polyurethane Foam } & $21 \%$ & $1 ”(25.4 \mathrm{~mm})$ & $0.05(1.3)$ \\
\hline & $23 \%$ & 9” (228 mm) & $0.27(6.9)$ \\
\hline \multirow[t]{2}{*}{ Polyisocyanurate Foam } & $21 \%$ & 2” (50.8 mm) & $0.07(1.8)$ \\
\hline & $30 \%$ & 12” (305 mm) & $0.13(3.3)$ \\
\hline \multirow[t]{3}{*}{ Silicone RTV } & $21 \%$ & $0.5 ”(12.7 \mathrm{~mm})$ & $0.01(0.3)$ \\
\hline & $24 \%$ & $2.6 ”(66.0 \mathrm{~mm})$ & $0.02(0.5)$ \\
\hline & $30 \%$ & 12” (305 mm) & $0.02(0.5)$ \\
\hline
\end{tabular}

${ }^{\mathbf{a}}$ Data for oxygen concentration effect comparison only, not to be considered standard values for listed material

b Data based upon specimens tested per ISO14624-1 with specimen dimensions 12” (305 mm) length and 2.5” (64 mm) width

${ }^{\mathrm{c}}$ Data derived from testing at the NASA - George C. Marshall Space Flight Center

\section{Pressure Effects}

Combustible materials, with few exceptions, burn far more readily and rapidly in oxygen systems with elevated pressures. The use pressure within in oxygen system should be minimized to the lowest allowable. Table 2 shows the effects on the burning of metals as the test system pressures are increased. 


\section{TABLE 2: Flammability of Metals by Pressure in an Oxygen Environment ${ }^{\mathrm{a}, \mathrm{b}, \mathrm{c}}$}

\begin{tabular}{|c|c|c|c|}
\hline Material & Test Pressure & $\begin{array}{l}\text { 12-inch (305 mm) } \\
\text { Rod Burn Length }\end{array}$ & $\begin{array}{c}\text { Burn Rate } \\
\text { in } / \mathrm{sec}(\mathrm{mm} / \mathrm{sec})\end{array}$ \\
\hline Bronze/Aluminum & $50 \overline{p s i}(345 \mathrm{kPa})$ & 0” $(0 \mathrm{~mm})$ & $0.0(0.0)$ \\
\hline Mixture & 100 psi (689 kPa) & 12” (305 mm) & $0.3(7.6)$ \\
\hline \multirow[t]{2}{*}{ Aluminum 4043} & 25 psi (172 kPa) & 4.4” (111.8 mm) & $0.6(15.2)$ \\
\hline & 50 psi (345 kPa) & $12 ”(305$ mm) & $1.1(27.9)$ \\
\hline \multirow[t]{2}{*}{316 Stainless Steel } & 500 psi (3447 kPa) & 1.7” (43.2 mm) & $0.3(7.6)$ \\
\hline & 1,000 psi (6895 kPa) & 12” (305 mm) & $0.4(10.2)$ \\
\hline \multirow[t]{2}{*}{304 Stainless Steel } & 500 psi (3447 kPa) & $3.8 ”(96.5$ mm) & $0.3(7.6)$ \\
\hline & 1,000 psi (6895 kPa) & 12” (305 mm) & $0.4(10.2)$ \\
\hline \multirow[t]{2}{*}{ 316L Stainless Steel } & 250 psi (1724 kPa) & 2.6” (66.0 mm) & $0.2(5.1)$ \\
\hline & 1,000 psi (6895 kPa) & 12” (305 mm) & $0.4(10.2)$ \\
\hline
\end{tabular}

${ }^{\text {a }}$ Data for pressure effects comparison only, not to be considered standard values for listed material

' Data based upon rods tested per ASTM G 124 and ISO14624-4 with rod dimensions 12" length, 0.125" diameter

${ }^{\mathrm{c}}$ Data derived from testing at the NASA - George C. Marshall Space Flight Center

\section{Temperature Effects}

Temperature affects on combustible materials, with very few exceptions, are analogous to pressure affects in that materials burn far more readily and rapidly in a gaseous oxygen environment as the system temperature is increased. Designers of gaseous oxygen systems should minimize the system temperature, with ambient temperature being ideal. Note that temperatures can increase substantially above the initial temperature during normal system operations by factors such as the effectiveness of the insulation and the frictional heating that occurs in normal system operation. Table 3 demonstrates the affects of temperature on the burning of metals in an upward flammability test. 


\section{TABLE 3: Flammability of Metals by Temperature in Oxygen ${ }^{\text {a,b,c }}$}

\begin{tabular}{|c|c|c|c|c|}
\hline $\begin{array}{c}\text { Material } \\
\text { Identification }\end{array}$ & $\begin{array}{l}\text { Test Pressure } \\
\text { psi (kPa) }\end{array}$ & $\begin{array}{c}\text { Test } \\
\text { Temperature }\end{array}$ & $\begin{array}{l}\text { 12" Rod Average } \\
\text { Burn Length }\end{array}$ & $\begin{array}{c}\text { Burn Rate } \\
\text { in } / \mathrm{sec}(\mathrm{mm} / \mathrm{sec})\end{array}$ \\
\hline$\overline{\text { 304L Stainless }}$ & $500(3447)$ & $\left.7 \overline{5^{\circ} \mathrm{F}\left(297^{\circ} \mathrm{K}\right.}\right)$ & $4 ”(102 \mathrm{~mm})$ & $0.35(8.9)$ \\
\hline Steel & 500 (3447) & $1,000^{\circ} \mathrm{F}\left(811^{\circ} \mathrm{K}\right)$ & 12” (305 mm) & $0.43(10.9)$ \\
\hline $15-5 \mathrm{PH}$ & 500 (3447) & $75^{\circ} \mathrm{F}\left(297^{\circ} \mathrm{K}\right)$ & $2.9 ”(74 \mathrm{~mm})$ & $0.33(8.4)$ \\
\hline Stainless Steel & 500 (3447) & $1,000^{\circ} \mathrm{F}\left(811^{\circ} \mathrm{K}\right)$ & 12” (305 mm) & 0.35 (8.9) \\
\hline Inconel ${ }^{\mathrm{TM}} 718$ & $\begin{array}{l}750(5171) \\
750(5171)\end{array}$ & $\begin{array}{c}75^{\circ} \mathrm{F}\left(297^{\circ} \mathrm{K}\right) \\
1.700^{\circ} \mathrm{F}\left(1200^{\circ} \mathrm{K}\right)\end{array}$ & $\begin{array}{l}\text { 4.2” }(107 \mathrm{~mm}) \\
12 ”(305 \mathrm{~mm})\end{array}$ & $\begin{array}{c}0.35(8.9) \\
0.60(15.2)\end{array}$ \\
\hline 316 Stainless & 500 (3447) & $75^{\circ} \mathrm{F}\left(297^{\circ} \mathrm{K}\right)$ & 5.6” (142 mm) & $0.34(8.6)$ \\
\hline Steel & 500 (3447) & $1,000^{\circ} \mathrm{F}\left(811^{\circ} \mathrm{K}\right)$ & 12” (305 mm) & 0.37 (9.4) \\
\hline
\end{tabular}

${ }^{\mathrm{a}}$ Data for temperature effects comparison only, not to be considered standard values for listed material

'Data based upon rods tested per ASTM G 124 with rod dimensions 12” length, 0.125” diameter

${ }^{\mathbf{c}}$ Data derived from testing at the NASA - George C. Marshall Space Flight Center

The data presented above demonstrate that fire hazards are far greater in systems with enriched oxygen, higher pressures and increased temperatures than experienced in normal atmospheric conditions. These hazards must be minimized by improved system designs.

\section{Generalizations on Affects}

The ignition resistance and burn inhibition properties inherent in a material are determined by several factors. The following list provides generalized rules on the fire safety for materials in oxygen systems:

(1) The higher the oxygen concentration within the system, the more easily the system materials ignite and the more rapidly they burn once ignited. So, the lowest usable oxygen concentration is preferred.

(2) The higher the pressure witnessed by the material, the more easily the material ignites and the more rapidly it burns once ignited. So, the lowest usable pressure is preferred.

(3) The higher the temperature witnessed by the material, the more easily the material ignites and the more rapidly it burns once ignited. So, the lowest workable temperature is preferred.

(4) The smaller the thickness of a material, the more easily the material ignites and the more rapidly it burns once ignited. So, thicker materials are preferable to thinner ones.

(5) The higher the flow rate of oxygen passing over a material, the more easily the material ignites and the more rapidly it burns in the direction of the flow once ignited. So, flow rates within the system should be kept as low as functionally allowed. 


\section{Safe Oxygen Systems}

Safety must be a primary goal for any oxygen system design. There are four ground rules for designing safer oxygen systems, as described in the ASTM Technical and Professional Training (TPT) Course Fire Hazards in Oxygen Systems. These are:

Conservation - Conserve both oxygen and materials within the system.

Maximization - Maximize the use of the most burn-resistant materials available.

Minimization - Minimize the potential ignition sources that are inherent in all systems.

Utilization - Utilize good system design practices.

\section{Conserve Oxygen and Materials}

The first step in designing safer oxygen systems is the conservation of oxygen and materials. The safest systems will conserve, or minimize, the amount of oxygen in the system. Less oxygen within a system minimizes the likelihood of ignition, and allows for quenching in case a fire does begin. Minimizing the amount of oxygen within a system can be accomplished in three ways: (1) Minimizing the system pressure by pressurizing the system no higher than absolutely necessary. (2) Using the lowest concentration of oxygen permitted for the application. (3) Designing the system providing for the shortest flow path of oxygen.

The safest oxygen systems will also minimize the amount of materials within the system. Less material within a system provides less fuel to burn. However, this factor can be misleading. In general, thicker materials are less likely to ignite than thinner ones. Therefore, the ignition hazard of a material must be weighed against the safety of utilizing less fuel within a system.

\section{Maximize Good Materials}

Poor material choices can greatly increase the likelihood of a fire occurring in an oxygen system. Some materials are more difficult to ignite than others and, when ignited, are more resistant to sustained burning. Materials also vary in the amount of energy released when they burn. Therefore, careful selection of materials can lessen the chances of ignition and enhance the burn resistance of a system, thus limiting the amount of damage resulting from a fire. Despite the fact that heat sources can be inherent to an oxygen system or its surroundings, design elements can limit the amount, or dissipate altogether, the heat within the system.

Several factors enter into the decision process for selecting the materials to be used in an oxygen system. However, the issue of the compatibility of the materials with the oxygen fluid is the only issue considered in this paper. Materials compatibility is an important factor for the safety of oxygen systems. Materials compatibility not only covers the potential chemical breakdown of a material with oxygen, but also encompasses the resistance of the material to ignition and burning.

The most compatible materials for oxygen environments possess the following properties: 
1. Difficult to ignite

2. Burn with low heat-of-combustion

3. Self-extinguish quickly once ignited

4. Burn slowly

The above listed properties are all determined by testing. Oxygen systems are not new, so extensive test data generated by the government and private industries already exist. However, newer materials, and even some older ones, have no test data. Therefore, it is important to generate new data for desired materials. Caution: The compatibility of untested materials is unknown. They cannot be determined by similarity to other materials whose properties are known, whether the similarity is in composition, physical properties, etc. Slight differences can drastically change the oxygen compatibility of a material.

Testing, and not evaluation, is the only method by which safe materials can be chosen. However, there is no decisive test or evaluation method that will clearly indicate the best materials for use in oxygen. Several test techniques have been developed to help determine which materials will probably be safer for specific applications in oxygen systems. These tests demonstrate either the ease of ignition or the tendency for sustained burning of the material.

The Ambient Pressure Liquid Oxygen Mechanical Impact Test, per ASTM D 2512, is one of the oldest and is still used today. This test involves dropping a metal plummet onto a disk of the material that is immersed in liquid oxygen. Materials that are very incompatible with oxygen will burn when the energy from the falling plummet is transferred to the sample. This burn, or reaction, is witnessed by the test operator. The reaction can be a visible flash, audible report, appearance of charring on the surface of the sample, or combination of these. Figure 2 shows a diagram of the section of the test fixture where the plummet will strike the material sample. Figure 3 shows the tester in operation at NASA MSFC. Figure 4 shows a severe reaction that can happen with a material that is not compatible with liquid oxygen, which clearly demonstrates the importance of testing! 


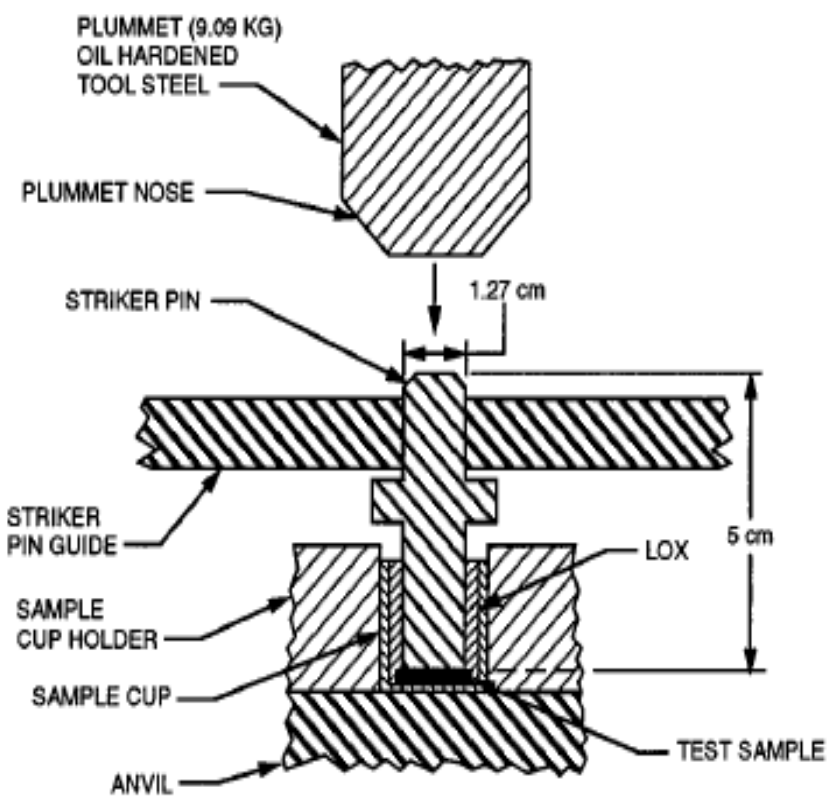

Figure 2:

Ambient Mechanical Impact Test Fixture

(From NASA-STD-6001)

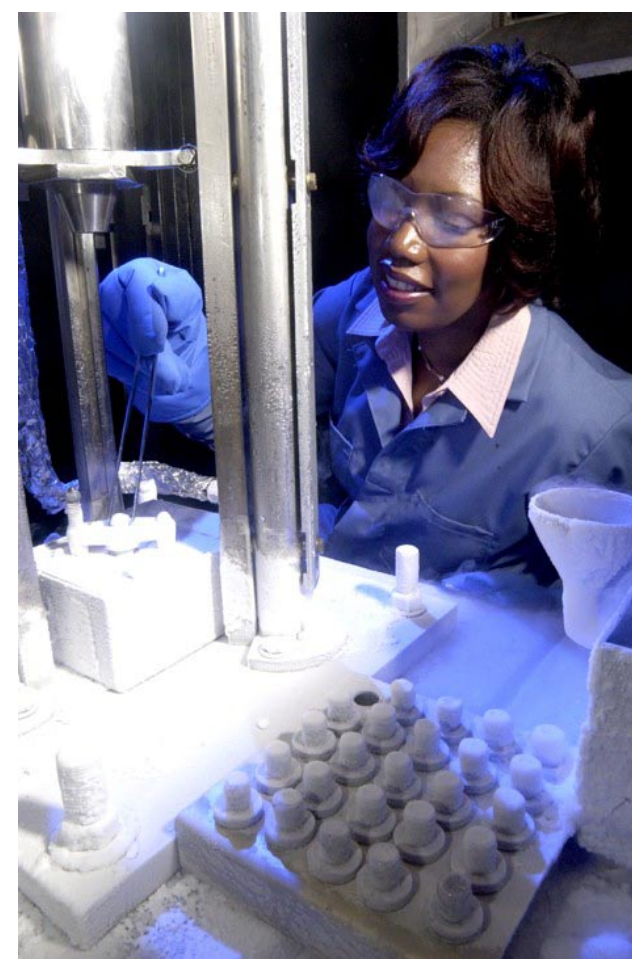

Figure 3:

Ambient Mechanical Impact Tester In Operation

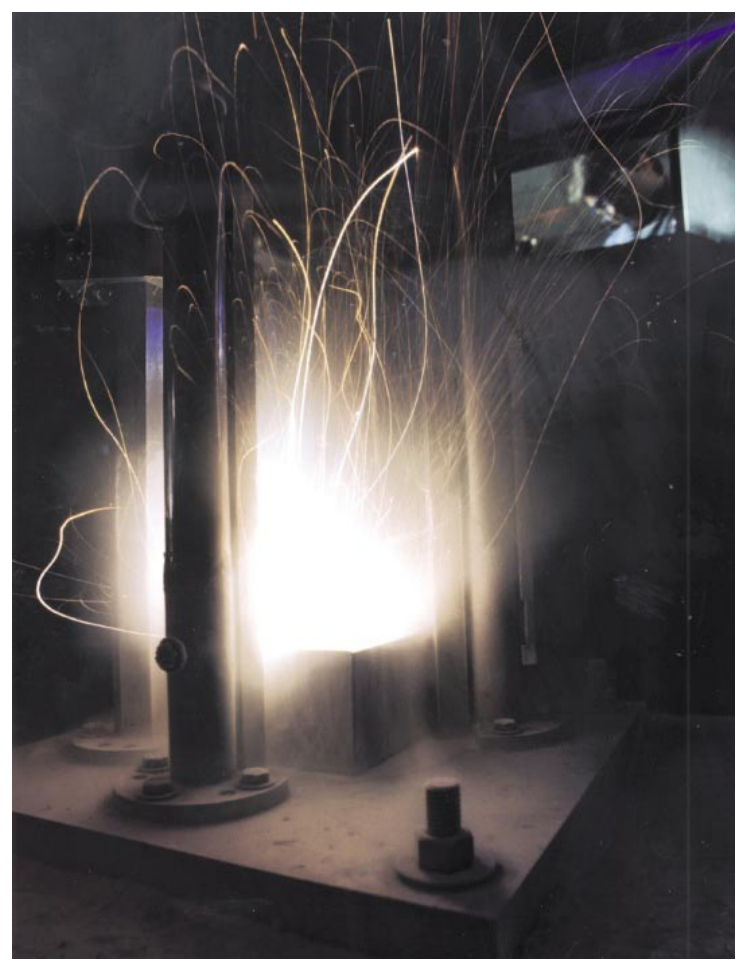

Figure 4:

Ambient Mechanical Impact Tester Showing a Severe Reaction 
After several years of oxygen systems failure investigations, this one test proved to be insufficient for determining if a material is safe for use in every application within an oxygen system. This Ambient Pressure Mechanical Impact Test, in fact, did not adequately address elevated pressure scenarios because several materials that passed the test were burning in highpressure oxygen systems. The tester was later modified to perform the mechanical impacts in high-pressure oxygen. The new tester, the High Pressure Liquid and Gaseous Oxygen Mechanical Impact Tester, which is operated per ASTM G 86, performs impact testing at pressures up to $10,000 \mathrm{psi}(68,948 \mathrm{kPa})$. The tester works basically the same way as the ambient pressure tester, except that this test fixture seals a head onto a base in order to hold the elevated test pressure. The tester was again modified to test materials in gaseous oxygen and at elevated temperatures. The test setup can be seen in Figure 5.

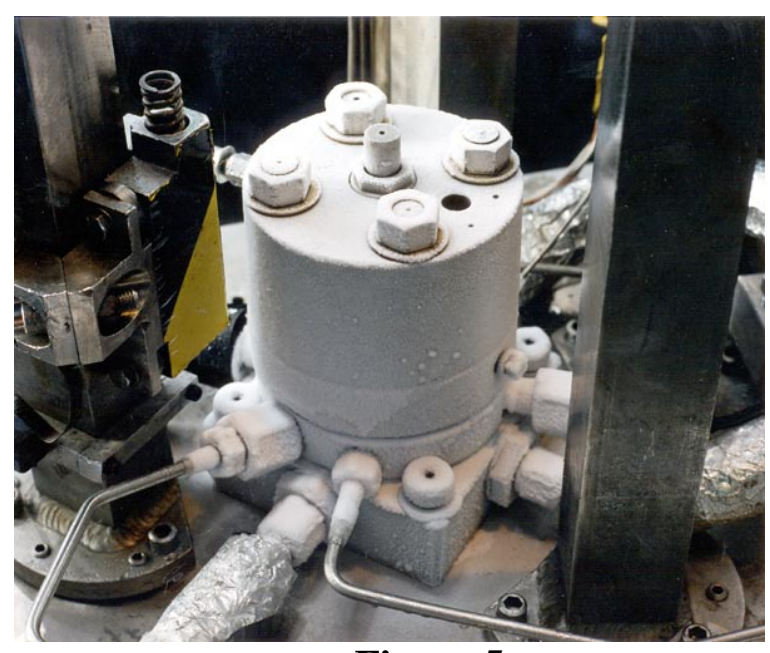

Figure 5:

High Pressure Mechanical Impact Tester Head Bolted to Base to Sustain Pressure

The Mechanical Impact Test has also, over time, proven to be insufficient. The test provides useful data for applications where actual impacts occur within the system, such as a valve material shutting against a valve seat. The test does not, however, provide useful information for other ignition scenarios. The Mechanical Impact Test also does not differentiate well between the metals that are very compatible with oxygen and those that are minimally compatible. In order to provide more useful data, several new test methods have been developed.

The Promoted Ignition Test, or Combustion Behavior of Metallic Materials in Oxygen per ASTM G 124, has become the new baseline standard for determining if a material is safe in an oxygen environment. This test uses a $1 / 8$-inch $(3.2 \mathrm{~mm})$ diameter rod of the candidate material hanging vertically in a test chamber. The rod is surrounded by oxygen and ignited at the bottom by an aluminum or magnesium promoter. The test demonstrates the behavior of a material once 
burning is initiated and is used to determine which materials do not ignite, or if ignited, which will or will not exhibit self-sustained burning.

The ASTM G 124 Promoted Ignition Test requires a rod of at least 4-inches $(102 \mathrm{~mm})$ in length, with a diameter of $1 / 8$-inch $(3.2 \mathrm{~mm})$. The promoter, connected to the bottom of the rod, is initiated and the sample rod is observed for its burn characteristics, primarily its burn length. Self-sustained combustion, as research has confirmed, occurs if the sample burns more than 1.2 inches $(30 \mathrm{~mm})$. Samples that burn more than this are considered unacceptable for unlimited use in an oxygen system at the test pressure. However, limited use of that material can be allowed under certain circumstances, which will be discussed later. A diagram of the Ambient Temperature Promoted Ignition Tester is shown in Figure 6. A photograph of a sample being loaded into the NASA-MSFC Elevated Temperature Promoted Ignition Tester is shown in Figure 7.

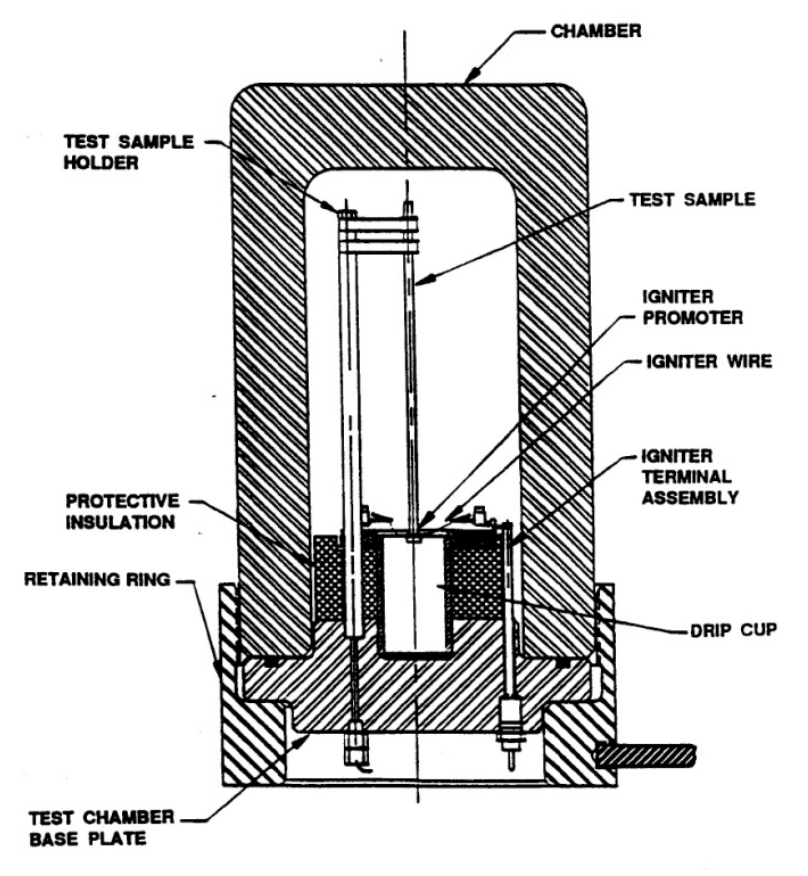

Figure 6:

Promoted Ignition Test Fixture

(From NASA-STD-6001) 


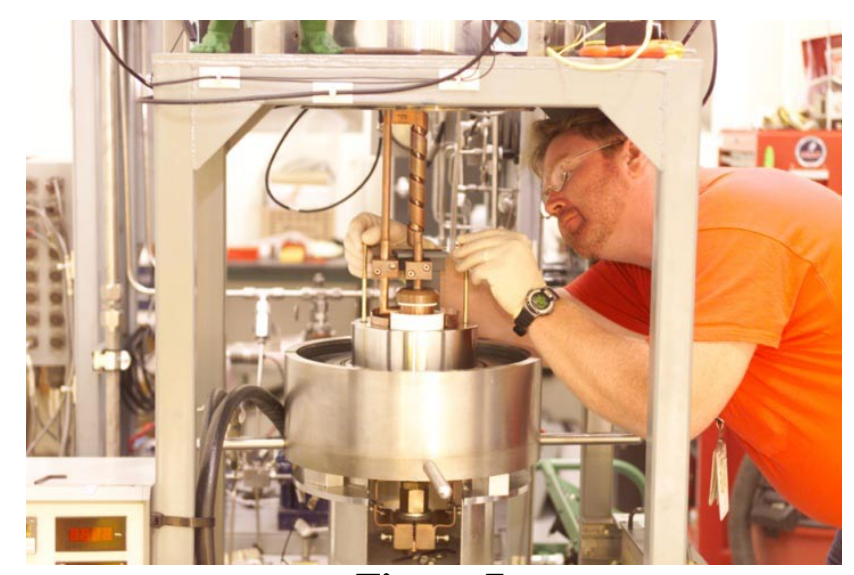

Figure 7:

Elevated Temperature Promoted Ignition Tester With Sample Rod in Heating Coil

The ASTM G 124 Promoted Ignition Test, due to its harshness, is still not a perfect test for materials in oxygen environments. Nonmetals that are essential seal materials for oxygen systems will not meet the acceptance criterion of this test. Also, the majority of the industry standard metals for oxygen systems, such as stainless steel alloys, do not meet this criterion at their typical use pressures. The harshness of the test has necessitated the development of a more realistic hazards evaluation process that will allow the use of materials that do not meet the acceptance criteria. This process is called an Oxygen Compatibility Assessment, and will be discussed later.

The Mechanical Impact Test and the Promoted Ignition Test provide the pressures at which a given material will ignite or burn. However, the two tests provide significantly different values for the lowest pressures at which a material will burn in oxygen. This is a result of the differences between an ignition test and a burning test. The determination of which test to use depends upon the use application planned for the material. The Mechanical Impact Test is more valuable for seal or seat materials that will actually be subjected to impact loads during normal system operation. The Promoted Ignition Test is more valuable for materials that will form the basic structure of the system.

Tables 4 and 5 provide summaries of data generated at the NASA - George C. Marshall Space Flight Center for selected materials in both of these tests. The data clearly show that the pressure required for a given material to exhibit self-sustained burning is much lower than the pressure that is required to ignite that material by means of a mechanical impact.

\section{Selection of Metals versus Nonmetals}

The selection of both metals and nonmetals is important, and each is important for its specific application. Due to their inherent structural strength, the vast majority of the materials in oxygen systems will be metals. However, nonmetals are important for applications such as valve seals and seats, lubricants, or applications where rigid materials cannot be used. Metals are 
generally more compatible with oxygen than nonmetals, but metals tend to burn much more violently, burn for longer durations, and burn at much higher temperatures. Both metals and nonmetals become more incompatible with oxygen as the pressures and/or temperatures within the system increase.

An oxygen system designer must choose the best materials by considering all of the factors involved, especially compatibility under the use conditions. The metals that tend to be the most compatible include nickel alloys, copper, brass and bronze. These metals are more difficult to ignite and, once ignited, tend to burn with the lowest heats of combustion. The metals that are more easily ignited, thus should be avoided, include magnesium, titanium and many aluminum alloys. The maximum use pressure within the system will drive the material choices.

The most commonly used nonmetals in oxygen systems are elastomers, lubricants, ceramics and carbon fiber materials. Each of these has its own application within the system. Elastomes are important for providing seals within a pressurized system. The seals must withstand the system pressure and be compatible with oxygen at the highest use pressure. The best elastomeric compounds are typically the fluorinated polymers, which as shown in Table 4, tend to be the more difficult to ignite and burn with a lower heat of combustion.

Lubricants are sometimes used in oxygen systems for pipe threads and other places where metal meets metal. However, lubricant use must follow two basic rules: (1) Use only when it is absolutely necessary, and (2) Use only the smallest workable amount. Lubricants pose several risks within a system because many are flammable in oxygen, and lubricants become contaminants if they enter into the oxygen stream. If a lubricant is absolutely necessary, then fluorinated lubricants are currently the best choices.

Ceramic materials are generally oxidized compounds and tend to be compatible with oxygen. However, the use of ceramics is limited because they are typically very fragile. Most oxygen systems need to be able to withstand internal temperature fluctuations and outside temperature and humidity changes as part of their normal operation. Ceramics do not undergo changes well, and so their usefulness is limited.

Carbon fiber composite materials, also known as graphite epoxies, have traditionally been shunned from oxygen systems because the binder, or matrix, materials are typically incompatible with oxygen. However, laboratory testing has demonstrated that some of these can be used in oxygen systems. Utilizing graphite epoxy composites is advantageous because of their low weight and high strength. Unfortunately, the factors that make graphite epoxy materials acceptable for use in oxygen systems are not well understood. Many variables inherent with composites have strong influences on their oxygen compatibility, namely binder material, layup, cure, shape, etc.

Materials which are not compatible with oxygen can be used effectively as secondary materials for oxygen service, thus reducing the cost or weight of the system. These secondary materials are not directly in contact with the oxygen fluid, i.e., not oxygen wetted, but can support the materials that are. Composites and ceramic materials have successfully been used as structural 
support for metals that cannot withstand the system pressures at their use pressures. A good example of this is a composite overwrapped oxygen tank.

Special care must be taken with nonmetals if they are used within a breathing oxygen system because some materials can produce toxic products that can enter into the oxygen stream, and thus, into the lungs of the user. Fluorinated elastomers and lubricants can produce toxic fluorinated products, especially if any small burn within the system allows combustion byproducts to enter the gas stream. It should be noted, however, that the fluorinated compounds have lower heats of combustion if ignited. Therefore, fluorinated polymers and lubricants tend to be the most preferable for use in oxygen systems.

The test data provided in Tables 4 and 5 clearly show that several classes of materials work well in oxygen systems, and several other classes of materials should be avoided. The data in these tables can be used for determining the materials that are best able to support the use conditions.

Table 4: Minimum Pressures Required to Ignite or Burn Common Metals as Determined by Promoted Ignition Test and Mechanical Impact Test ${ }^{\mathrm{a}}$

\begin{tabular}{|c|c|c|c|}
\hline Material & $\begin{array}{c}\text { Oxygen } \\
\text { Condition }\end{array}$ & $\begin{array}{l}\text { Promoted Ignition Test - } \\
\text { On Average, Burning Is Not } \\
\text { Sustained Below Pressure }\end{array}$ & $\begin{array}{l}\text { Mechanical Impact Test - } \\
\text { On Average, No Ignition } \\
\text { Occurs Below Pressure }\end{array}$ \\
\hline \multirow{2}{*}{ Aluminum 2024} & GOX & Ambient & 1,500 psi (10342 kPa) \\
\hline & LOX & $\mathrm{I} / \mathrm{A}^{\mathrm{b}}$ & 1,500 psi (10342 kPa) \\
\hline \multirow[t]{2}{*}{ Aluminum 2090} & GOX & Ambient & 500 psi (3447 kPa) \\
\hline & LOX & $\mathrm{I} / \mathrm{A}^{\mathrm{b}}$ & 500 psi (3447 kPa) \\
\hline \multirow[t]{2}{*}{ Aluminum 2219} & GOX & Ambient & 1,500 psi (10342 kPa) \\
\hline & LOX & $\mathrm{I} / \mathrm{A}^{\mathrm{b}}$ & 50 psi (345 kPa) \\
\hline \multirow[t]{2}{*}{ Aluminum 6061} & GOX & Ambient & Ambient \\
\hline & LOX & $\mathrm{I} / \mathrm{A}^{\mathrm{b}}$ & Ambient \\
\hline \multirow[t]{2}{*}{ Brass } & GOX & 10,000 psi (68948 kPa) & 10,000 psi (68948 kPa) \\
\hline & LOX & $\mathrm{I} / \mathrm{A}^{\mathrm{b}}$ & 10,000 psi (68948 kPa) \\
\hline \multirow[t]{2}{*}{ Copper 12200} & GOX & 10,000 psi (68948 kPa) & 10,000 psi (68948 kPa) \\
\hline & LOX & $\mathrm{I} / \mathrm{A}^{\mathrm{b}}$ & 10,000 psi $(68948 \mathrm{kPa})$ \\
\hline \multirow[t]{2}{*}{ Haynes 214} & GOX & 1,000 psi (6895 kPa) & 10,000 psi (68948 kPa) \\
\hline & LOX & $\mathrm{I} / \mathrm{A}^{\mathrm{b}}$ & 10,000 psi (68948 kPa) \\
\hline \multirow{2}{*}{ Inconel 718} & GOX & 500 psi (3447 kPa) & 10,000 psi (68948 kPa) \\
\hline & LOX & $\mathrm{I} / \mathrm{A}^{\mathrm{b}}$ & 10,000 psi (68948 kPa) \\
\hline
\end{tabular}




\begin{tabular}{|c|c|c|c|}
\hline Magnesium & $\begin{array}{l}\text { GOX } \\
\text { LOX }\end{array}$ & $\begin{array}{c}\text { Below Ambient } \\
\text { I/A }\end{array}$ & $\begin{array}{l}\text { Below Ambient } \\
\text { Below Ambient }\end{array}$ \\
\hline Monel K-400/K-500 & $\begin{array}{l}\text { GOX } \\
\text { LOX }\end{array}$ & $\begin{array}{c}\text { 10,000 psi }(68948 \mathrm{kPa}) \\
\mathrm{I} / \mathrm{A}^{\mathrm{b}}\end{array}$ & $\begin{array}{l}10,000 \mathrm{psi}(68948 \mathrm{kPa}) \\
10,000 \mathrm{psi}(68948 \mathrm{kPa})\end{array}$ \\
\hline Nickel & $\begin{array}{l}\text { GOX } \\
\text { LOX }\end{array}$ & $\begin{array}{c}\text { 10,000 psi (68948 kPa) } \\
\text { I/A } \mathrm{A}^{\mathrm{b}}\end{array}$ & $\begin{array}{l}10,000 \mathrm{psi}(68948 \mathrm{kPa}) \\
10,000 \mathrm{psi}(68948 \mathrm{kPa})\end{array}$ \\
\hline Stainless Steel 17-4 & $\begin{array}{l}\text { GOX } \\
\text { LOX }\end{array}$ & $\begin{array}{c}400 \mathrm{psi}(2758 \mathrm{kPa}) \\
\text { I// } \mathrm{A}^{\mathrm{b}}\end{array}$ & $\begin{array}{l}\text { 5,000 psi (34474 kPa) } \\
5,000 \mathrm{psi}(34474 \mathrm{kPa})\end{array}$ \\
\hline Stainless Steel 304L & $\begin{array}{l}\text { GOX } \\
\text { LOX }\end{array}$ & $\begin{array}{c}250 \text { psi }(1724 \mathrm{kPa}) \\
\mathrm{I} / \mathrm{A}^{\mathrm{b}}\end{array}$ & $\begin{array}{l}10,000 \mathrm{psi}(68948 \mathrm{kPa}) \\
10,000 \mathrm{psi}(68948 \mathrm{kPa})\end{array}$ \\
\hline Stainless Steel 316 & $\begin{array}{l}\text { GOX } \\
\text { LOX }\end{array}$ & $\begin{array}{c}400 \mathrm{psi}(2758 \mathrm{kPa}) \\
\mathrm{I} / \mathrm{A}^{\mathrm{b}}\end{array}$ & $\begin{array}{l}10,000 \mathrm{psi}(68948 \mathrm{kPa}) \\
10,000 \mathrm{psi}(68948 \mathrm{kPa})\end{array}$ \\
\hline Stainless Steel 420 & $\begin{array}{l}\text { GOX } \\
\text { LOX }\end{array}$ & $\begin{array}{c}750 \mathrm{psi}(5171 \mathrm{kPa}) \\
\text { I/A }{ }^{\mathrm{b}}\end{array}$ & $\begin{array}{l}10,000 \mathrm{psi}(68948 \mathrm{kPa}) \\
10,000 \mathrm{psi}(68948 \mathrm{kPa})\end{array}$ \\
\hline Stainless Steel 440C & $\begin{array}{l}\text { GOX } \\
\text { LOX }\end{array}$ & $\begin{array}{c}3,000 \mathrm{psi}(20684 \mathrm{kPa}) \\
\mathrm{I} / \mathrm{A}^{\mathrm{b}}\end{array}$ & $\begin{array}{l}10,000 \mathrm{psi}(68948 \mathrm{kPa}) \\
10,000 \mathrm{psi}(68948 \mathrm{kPa})\end{array}$ \\
\hline Titanium & $\begin{array}{l}\text { GOX } \\
\text { LOX }\end{array}$ & $\begin{array}{c}\text { Below Ambient } \\
\mathrm{I} / \mathrm{A}^{\mathrm{b}}\end{array}$ & $\begin{array}{l}\text { Below Ambient } \\
\text { Below Ambient }\end{array}$ \\
\hline
\end{tabular}

${ }^{\text {a }}$ Data for comparison purposes only, not to be considered standard values for listed material

b I/A - Insufficient Test Data Available 
Table 5: Minimum Pressures Required to Ignite or Burn Common Nonmetals in the Promoted Ignition Test and Mechanical Impact Test ${ }^{\mathrm{a}}$

Material

Acrylic Sheet

Butyl Rubber

Carbon Fiber/Epoxy

(Graphite Epoxy)

Polytetrafluoroethylene

Fiberglass

Fluorinated Lubricants

(PCTFE)

Molybdenum Disulfide

Neoprene Rubber

Nitrile Rubber

Polyimide (Kapton ${ }^{\mathrm{TM}}$, etc.)

Polyvinylchloride (PVC)

Silicon Carbide

Silicone Rubber Sheet

\begin{tabular}{l}
$\begin{array}{c}\text { Oxygen } \\
\text { Condition }\end{array}$ \\
\hline GOX \\
LOX
\end{tabular}

GOX

LOX

GOX

LOX

GOX

LOX

GOX

LOX

GOX

LOX

GOX

LOX

GOX

LOX

GOX

LOX

GOX

LOX

GOX

LOX

GOX

LOX

GOX

LOX
Promoted Ignition Test -

Typically Burning is Not

Sustained Below Pressure

$\mathrm{I} / \mathrm{A}^{\mathrm{C}}$

$\mathrm{I} / \mathrm{A}^{\mathrm{c}}$

$\mathrm{I} / \mathrm{A}^{\mathrm{c}}$

$\mathrm{I} / \mathrm{A}^{\mathrm{C}}$

$\mathrm{I} / \mathrm{A}^{\mathrm{C}}$

$\mathrm{I} / \mathrm{A}^{\mathrm{C}}$
$<50$ psi $(<345 \mathrm{kPa})$
$\mathrm{I} / \mathrm{A}^{\mathrm{C}}$

$\mathrm{I} / \mathrm{A}^{\mathrm{C}}$
$\mathrm{I} / \mathrm{A}^{\mathrm{C}}$

$\mathrm{I} / \mathrm{A}^{\mathrm{c}}$

$\mathrm{I} / \mathrm{A}^{\mathrm{C}}$

$\mathrm{I} / \mathrm{A}^{\mathrm{C}}$

$\mathrm{I} / \mathrm{A}^{\mathrm{C}}$

$\mathrm{I} / \mathrm{A}^{\mathrm{C}}$

$\mathrm{I} / \mathrm{A}^{\mathrm{C}}$

$\mathrm{I} / \mathrm{A}^{\mathrm{C}}$

$\mathrm{I} / \mathrm{A}^{\mathrm{C}}$

$\mathrm{I} / \mathrm{A}^{\mathrm{C}}$
$\mathrm{I} / \mathrm{A}^{\mathrm{C}}$

Unsafe At All Pressures

$\mathrm{I} / \mathrm{A}^{\mathrm{C}}$

$\mathrm{I} / \mathrm{A}^{\mathrm{c}}$

$\mathrm{I} / \mathrm{A}^{\mathrm{C}}$
Mechanical Impact Test

Typically No Ignition

Occurs Below Pressure

5,000 psi (34474 kPa)

5,000 psi (34474 kPa)

40 psi (276 kPa)

Unsafe At All Pressures

10,000 psi $(68948 \mathrm{kPa})^{\mathrm{b}}$

5,000 psi (34474 kPa)

3,500 psi (24132 kPa)

1,500 psi (10342 kPa)

5,000 psi (34474 kPa)

5,000 psi (34474 kPa)

10,000 psi (68948 kPa)

8,000 psi (55158 kPa)

4,000 psi (27579 kPa)

4,000 psi (27579 kPa)

4,000 psi (27579 kPa)

4,000 psi (27579 kPa)

$<150$ psi $(<1034 \mathrm{kPa})$

$<150$ psi $(<1034 \mathrm{kPa})$

200 psi (1379 kPa)

Unsafe At All Pressures

$$
\mathrm{I} / \mathrm{A}^{\mathrm{c}}
$$

Unsafe At All Pressures

250 psi (1724 kPa)

250 psi (1724 kPa)

$\mathrm{I} / \mathrm{A}^{\mathrm{c}}$

\footnotetext{
${ }^{\mathbf{a}}$ Data for comparison purposes only, not to be considered standard values for listed material)
} 
${ }^{\mathbf{b}}$ Composite materials made from carbon fibers and epoxy binder are dependent upon the specific binder and the layup of the sheet. These values are for comparison purposes only. ${ }^{\mathrm{c}} \mathrm{I} / \mathrm{A}$ - Insufficient Test Data Available

Several newer tests are being used to provide supplemental information on materials for use in oxygen service. These tests include the Oxygen Index Test (ASTM G 125), Autogenous Ignition Temperature Test (ASTM G 72), Gaseous Pneumatic Impact Test (ASTM G 74), and Elevated Temperature Promoted Ignition Test (ASTM G 124, revisions after 2009). The values of these tests are uncertain at present, and the data generated are being scrutinized to determine if any strong correlations can be found between test results and the successful utilization of materials in oxygen environments.

\section{Configuration Dependence}

The energy required to ignite a material or sustain its burning is not a fixed value but is influenced by several factors, whether dealing with metals or nonmetals. The amount of energy required to ignite a material, based upon the minimum temperature and pressure at which it will ignite, is determined by the thickness of the material, the shape of the part produced by the material, and the surface configuration. Metals are specifically sensitive to composition variations and heat treatments. Nonmetals are sensitive to cure conditions, batch/lot variability and the age of the material.

The flammability of a metal is strongly influenced by its configuration, or the size and shape of the part. Solid metals are the most resistant to ignition and burn the least if ignited. Metal parts with higher surface areas will burn more easily than those with less surface area. If a metal tube and a metal rod of the same material and diameter are tested, the tube will ignite more easily. Metal mesh materials, such as filter materials, are the easiest of all configurations to ignite. For example, a 316 stainless steel rod will not ignite until the pressure is generally more than $400 \mathrm{psi}$ (2758 kPa), but a 316 stainless steel mesh filter material shaped into a rod of the same dimensions will ignite in oxygen below atmospheric pressure.

The variability of the flammability of a material in different configurations is the primary reason that stainless steels are used extensively in high-pressure oxygen systems even though they are flammable under these pressures. Oxygen system components for high-pressure applications typically have think walls to withstand the stresses. This thickness is also advantageous for ignition resistance.

\section{Minimize Ignition Sources and Mechanisms}

An ideal oxygen system will have nothing inside that could create an ignition potential. There would be no contaminant, no floating debris, no metal shavings from pipe threading, and only pure oxygen entering into the system. This is the ideal scenario which does not exist in the real 
world. Therefore, steps must be taken when designing an oxygen system in order to minimize the effects of ignition sources and mechanisms that will certainly find their way into the system.

Ignition sources and mechanisms are materials or processes that can themselves ignite or cause ignition of other materials within the system. The most common ignition sources are contaminants in the system, and the most common ignition mechanisms are improper system designs that allow the system to be subjected to sufficient energy to create an ignition of existing materials during operations.

The safest oxygen systems are designed after consideration of the following issues: (1) Which ignition sources and/or mechanisms could be present in the system? (2) What is the severity of the hazards produced? (3) What hazards could arise from the worst-case scenario, such as any danger to humans or systems?

Several ignition sources and mechanisms have been determined, after many years of failure investigations, for oxygen systems. The list, provided below, is not complete but does represent the most common ignition sources and mechanisms, or at least, the ones that are currently understood. These are:

(1) Contamination (FOD)

(2) Particle impact

(3) Rapid pressurization

(4) Mechanical impact

(5) Friction

(6) Static discharge

(7) Electrical arc

(8) External heat

(9) External hazards

\section{Contamination}

A contaminant, commonly called FOD for foreign object debris, is any unwanted particle or bit of material that enters into the system. FOD is the most common ignition source. As dangerous as it is, contamination should be considered unavoidable and mitigation plans developed.

Sources of contamination include: (1) Dirt or debris entering the system during assembly. (2) Excess lubricants that leak from threading. (3) Metal flakes that emanate from the pipe threading during assembly. (4) Particles brought into the system in impure oxygen. (5) Particulates that emanate from within the system, such as by a breakdown of seals, flaking of vessel plating, valve friction shearing metal pieces, etc. (6) Items that have been dropped into the system by workers. Contamination is a significant factor in each ignition mechanism. 


\section{Particle Impact}

The particle impact ignition mechanism involves heat being generated by a particle striking the surface of another material with a velocity that will generate sufficient heat to ignite the particle or the material. This particle can be introduced during the assembly of the system, or by one released during system operation. This ignition mechanism generally requires a metal particle and metal surface to strike. Nonmetals are generally considered unable to be ignited by particle impact. Hard plastics have been ignited, although rarely, by this mechanism. Figure 8 shows one particle impact ignition scenario.

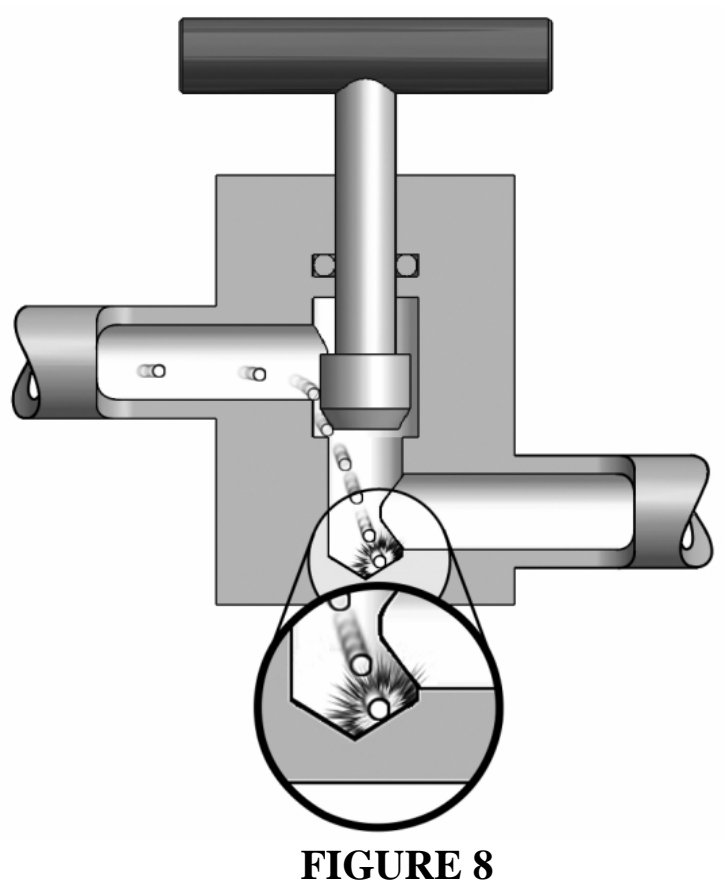

\section{Particle Impact Ignition Could Result from a Particle Striking a Flammable Part of a Valve - Note the Orifice Accelerating the Particle Increasing Ignition Probability}

(From NASA/TM-2007-213740)

The amount of laboratory research that has been conducted on this ignition mechanism is limited, and new research may change some of the assumptions. Current beliefs about oxygen dictate that four factors must be present before particle impact ignition can occur: (1) The system must be a gaseous oxygen system. (2) The particle must be one of the more flammable metals, such as aluminum, titanium, etc. (3) The flow rate of the oxygen gas must be greater than 45 meters/second (150 feet/second). (4) The particle must impact the surface of the material at full force and not be a glancing blow.

The particle impact ignition hazard can be mitigated by: (1) Cleaning oxygen system components specifically for oxygen service. (2) Threading pipes carefully so not to release particles. (3) Utilizing internal filter elements for trapping particles. (4) Regulating the oxygen flow rate to the lowest tolerable level. (5) Designing systems to produce flow paths that have 
minimal points where particles can strike at severe angles. (6) Minimizing components that can generate particles, such as rotating valves, sliding parts, etc.

\section{Rapid pressurization}

The rapid pressurization, also known as heat-of-compression or adiabatic compression, ignition mechanism involves extreme heat generated by the oxygen gas itself undergoing pressurization. The Ideal Gas Law and thermodynamic equations for an adiabatic process, i.e., no heat loss, demonstrate that if the oxygen gas pressure increases rapidly then the gas temperature increases rapidly. The formula for determining the final temperature by this process is given by:

$$
\mathrm{T}_{\mathrm{f}}=\mathrm{T}_{\mathrm{i}}\left(\mathrm{P}_{\mathrm{f}} / \mathrm{P}_{\mathrm{i}}\right)^{(\gamma-1) / \gamma} \text { where } \gamma \text { represents the adiabatic index of the gas, for } \mathrm{O}_{2}=1.40
$$

If the mechanism by which rapid pressurization is not carefully controlled, the temperature of the gas and surrounding materials can increase beyond the ignition point of the materials. Figure 9 illustrates this mechanism in a system.

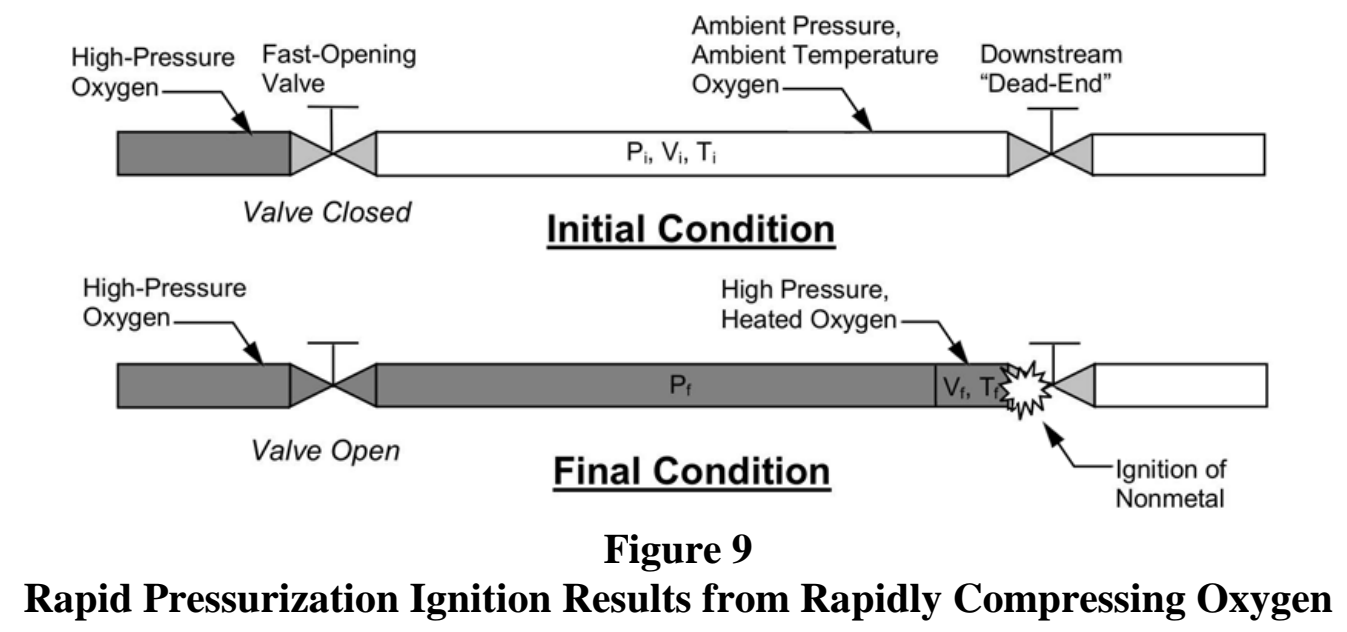

(From NASA/TM-2007-213740)

Rapid pressurization ignition is not possible unless three conditions are present:

(1) A significant pressure spike increases the pressure from near ambient to at least 500 psi

(3,447 kPa).

(2) Rapid pressurization occurs within a fraction of a second.

(3) A flammable nonmetal is present close to the highest temperature gas generated.

The final temperature resulting from rapid pressurization is very high. For example, starting from ambient pressure, the final temperature of rapidly pressurizing to 2,000 psi $(13,790 \mathrm{kPa})$ produces a temperature of $1,688^{\circ} \mathrm{F}\left(1193^{\circ} \mathrm{K}\right)$. And, rapidly pressurizing to 5,000 psi $(34,474$ $\mathrm{kPa}$ ) produces a temperature of $2,330^{\circ} \mathrm{F}\left(1550^{\circ} \mathrm{K}\right)$. Nonmetals are easy to ignite at these temperatures. 
The rapid pressurization ignition potential must be minimized in oxygen systems by good design practices, including: (1) Limiting pressurization rates, (2) Minimizing the amount of nonmetals, including contaminants, in areas affected by pressurization, (3) Burying nonmetals behind metal parts in the flow path, and (4) Compressing oxygen slowly in the vicinity of soft goods.

\section{Mechanical Impact}

The mechanical impact ignition mechanism involves heat energy generated when two objects collide. There are numerous collisions that occur with normal operations, such as valves closing, which are designed into the system. However, collisions sometimes occur with large pieces of contaminant debris or by parts of the system breaking free. These sources of mechanical impact must be mitigated. Figure 10 shows a mechanical impact ignition hazard that has resulted in a number of fires during an oxygen transfer process.

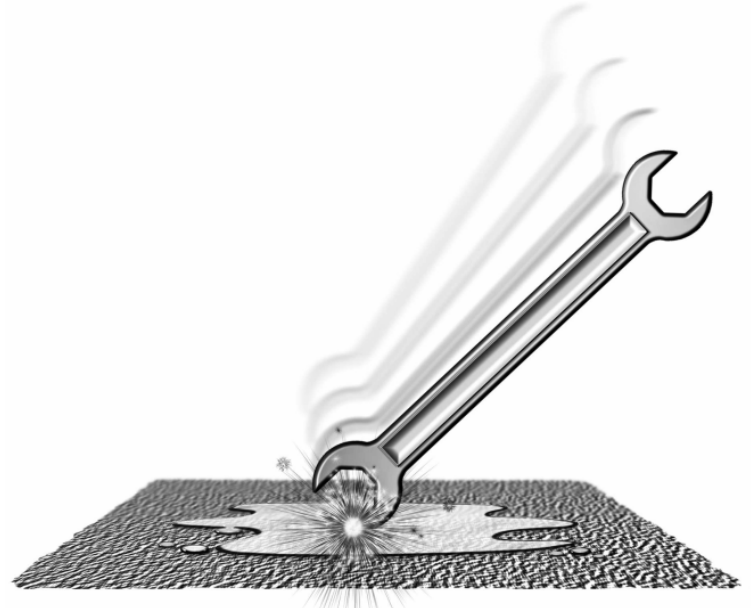

Figure 10

Mechanical impact Ignition Results from a Wrench Falling onto an Asphalt Pad Covered in Liquid Oxygen

(From NASA/TM-2007-213740)

The mechanical impact ignition mechanism is most commonly witnessed during the opening and closing of valves where heat is generated from the frequent slamming together of parts. A metal part impacting against a polymer seat can produce sufficient heat to ignite the seat. Two conditions are necessary for mechanical impact ignition: (1) A nonmetal or highly flammable metal must be impacted by another material such that its temperature rises above its auto-ignition temperature, (2) The impact must deliver a significant amount of energy, either by multiple impacts occurring rapidly or by one single strong impact. Valve materials are commonly subjected to multiple impacts, especially if polymer seal chatter occurs. Large foreign objects in the flow stream, however, typically lead to one forceful strike. 


\section{Friction}

The friction ignition mechanism involves the heat energy generated when two objects rub together. Frictional rubbing of two materials in oxygen can provide sufficient heat to ignite one of the materials in the friction load. In addition, heat generated in the friction process can ignite debris near the rubbing surfaces. A subset, and more severe case, of friction is galling between two metal parts. Figure 11 illustrates a condition in which friction ignition can occur in an oxygen system.

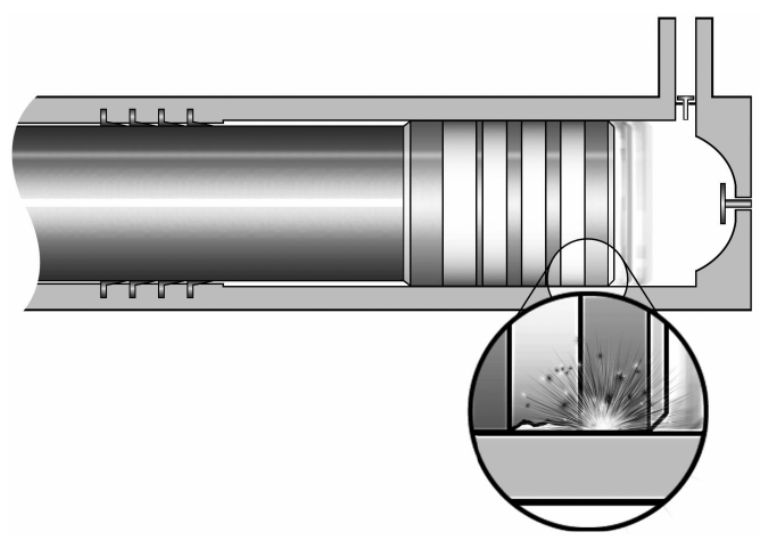

Figure 11

Frictional Ignition Occurs Due to Damaged or Worn Soft Goods Resulting in Metal to Metal Rubbing

(From NASA/TM-2007-213740)

Friction ignition can occur if three factors are present:

(1) Two metals are rubbing together.

(2) Rubbing must be at a high speed in order to generate enough heat to ignite one of the metals.

(3) The metals must undergo a high load, i.e., press together with enough force to make the rubbing severe.

Some components, such as check valves, regulators, and relief valves, may become unstable and chatter during use. Chattering can result in rapid oscillation of the moving parts within these components, creating a friction ignition hazard. The friction ignition hazard should be minimized by avoiding the rubbing together of two metals parts, or by slowing the rate at which they rub.

\section{Less Common Ignition Sources and Mechanisms}

Several ignition mechanisms are rarely witnessed in oxygen systems, but should not be ignored. These include static discharge, lightening strikes, explosions or tank ruptures in nearby systems, open flame fires that get close to the system, welding, and severe weather damage, as by hurricane, tornado, earthquake, flood, etc. Special considerations may be necessary if the oxygen system will be located in a hazard-prone area. 


\section{Ignition Happens but Nobody Knows Why, Formerly known as “Flow Friction”}

Oxygen system failure investigators sometimes really do not know why an ignition has occurred. The failure investigation clearly shows that something went wrong and one or more materials ignited. One historical theory stated that the rapid flow of gas across a polymer could heat the polymer to the point of ignition, which may create a kindling chain of burning that could lead to a catastrophic failure. This ignition mechanism became known as the flow friction ignition mechanism.

The flow friction ignition theory has now been determined to be a highly unlikely ignition mechanism. This ignition mechanism is discussed because this mechanism is frequently listed in literature. To date, flow friction has never led to the ignition of a material in a laboratory experiment, even after exhaustive laboratory testing under conditions ideal for creating an ignition by flow friction. It is now believed that flow friction ignition is actually caused by one or more mechanisms that could not be determined or are currently not understood.

The flow friction ignition mechanism assumed that three conditions were required:

(1) Oxygen must be at a pressure greater than 500 psi $(3,447 \mathrm{kPa})$

(2) Nonmetals must be present to ignite

(3) Rapid flow causes erosion, vibration, friction or similar mechanism for heating a nonmetal

Further research will be necessary in order to fully understand the actual ignition mechanism that has been called flow friction.

\section{Importance of Appropriate Cleaning}

An important factor in the safe use of an oxygen system is appropriate cleaning, which provides contamination avoidance. Contaminant particles can accumulate to dangerous levels that are easily ignited. The following are keys to clean oxygen systems:

(1) Use only oxygen system approved cleaning agents and techniques.

(2) Clean all parts prior to system assembly, if possible.

(3) Minimize the number of different materials used for assembly, such as seal materials, lubricants, etc. Users are more likely to notice an incorrect material when few are used.

(4) Visually inspect all components before use and reject any component that does not appear to be $100 \%$ clean.

(5) Avoid using vendor labeled "oxygen compatible” parts. The vendor claim must be independently verified or the part rebuilt using only oxygen compatible materials.

(6) Protect clean parts from contamination by keeping them covered until assembly, and assembling as many parts as possible in a clean area.

(7) Carefully assemble so that two surfaces rubbing together will not generate particulates that can enter into the system. 
(8) Use lubricants only when absolutely necessary, and ensure that the lubricants are oxygen compatible. Use the smallest amount of lubricant allowable.

(9) Ensure that verification testing of the cleanliness level has been performed and that the cleanliness level is within the allowable tolerance.

(10) Ensure that vent lines are guarded against contaminants entering the system.

(11) Use an inert gas to blow through the system in order to remove any stray particles prior to oxygen being introduced.

\section{Trivial Overview of an ASTM Oxygen Compatibility Assessment}

Students who attend the ASTM Technical and Professional Training class Fire Hazards in Oxygen Systems learn that an Oxygen Compatibility Assessment (OCA) is the applications part of determining if hardware is acceptable for use in contact with oxygen. An OCA is best described as a formal hazards analysis for the safety of specific materials and hardware in a defined oxygen environment. All of the information that has been presented to this point is the education needed in order to determine what is safe and what is unsafe for oxygen systems. The OCA is the point where the "rubber meets the road," where issues, solutions and recommendations are formally documented for use.

Many organizations, including ASTM, have over the years generated a number of standards and procedures that produce safer oxygen systems. These standards and procedures are used during the OCA to enhance system safety. The best education available on performing an OCA is by taking part in the ASTM course mentioned earlier.

An Oxygen Compatibility Assessment is a tool that leads the user through a step-by-step procedure for assessing the risks associated with an oxygen system. The OCA utilizes the system materials list, drawings of components, and system operating conditions to proceed through a structured risk assessment. The structural approach of the OCA helps prevent some areas from being overlooked while providing a structural approach to necessary remedies. An oxygen system designer will find that the OCA helps outline the known hazards that may be present, highlight areas that need further review, and provides safety improvement strategies.

An Oxygen Compatibility Assessment is not necessary in one specific case, one in which all of the materials used within the system are oxygen compatible at the maximum use temperatures and pressures of the system. The approach, however, allows very few materials to be used and almost all of these are expensive to purchase. The desire to allow a wider selection of materials, especially lighter weight and less expensive materials, necessitates the use of the OCA tool.

The Oxygen Compatibility Assessment involves several specific steps during the formal process. These steps are provided here with, for brevity, little information. This explanation is provided just to inform the reader of the existence of the OCA process and the information that the assessment will provide. Sufficient information that would allow the reader to produce an OCA has not been provided here. Anyone needing to produce an OCA is strongly encouraged to complete the ASTM TPT course.

An OCA is accomplished by following these steps for an oxygen system in which all of the conditions present are known: 
(1) Determining of the worst case operating conditions at each point within the system.

(2) Assessing the flammability of the oxygen-wetted materials at their "worst case" conditions.

(3) Evaluating potential ignition mechanisms and determining their probability of occurrence.

(4) Evaluating any kindling chain within the system, and determining the most severe possible affects.

(5) Determining the reaction effects, i.e., the severity of the worst potential outcome of a hazard, including human casualty, equipment destruction, etc.

(6) Compiling the list of hazards and determining methods of correcting them.

(7) Documenting the results for each hazard or component.

New information becomes available almost every day concerning oxygen systems hazards. This new information has necessitated updating the current ASTM TPT course, and this course update is in progress at the writing of this paper. The last course update from 2009 stopped at step (7) above. However, NASA-Marshall Space Flight Center has incorporated three additional steps into its OCA process, which will most likely be added to the next edition of the ASTM TPT course. These additional steps are as follows:

(8) Providing recommendations and required modifications for system safety improvements.

(9) Providing the limitations of the provided Oxygen Compatibility Assessment.

(10) Determining the safety of the hardware or system if it is built exactly as it has been proposed.

\section{Conclusions}

Oxygen systems are inherently dangerous and must only be designed by professionals who have a working knowledge of the intricacies inherent in these systems. The information provided in this paper serves to introduce neophytes in oxygen systems to important safety concerns. This paper does not provide sufficient information for the reader to design a new and safe oxygen system, or even to determine the safety of an existing one. It does serve to provide introductory information that will provide the reader with a basic understanding of oxygen systems, and background information that will allow the reader to understand the more detailed standards and procedures available on the subject. 


\section{References}

[1] ASTM D 2512, Standard Test Method for Compatibility of Materials with Liquid Oxygen, ASTM International, 100 Barr Harbor Drive, West Conshohocken, PA 19428-2959

[2] ASTM G 74, Standard Test Method for Ignition Sensitivity of Materials to Gaseous Fluid Impact, ASTM International, 100 Barr Harbor Drive, West Conshohocken, PA 19428-2959

[3] ASTM G 86, Standard Test Method for Determining Ignition Sensitivity of Materials to Mechanical Impact in Ambient Liquid Oxygen and Pressurized Liquid and Gaseous Oxygen Environments, ASTM International, 100 Barr Harbor Drive, West Conshohocken, PA 194282959

[4] ASTM G 124, Standard Test Method for Determining the Burning Behavior of Metallic Materials in Oxygen-Enriched Atmospheres, ASTM International, 100 Barr Harbor Drive, West Conshohocken, PA 19428-2959

[5] ASTM G 128, Standard Guide for Control of Hazards and Risks in Oxygen Enriched Systems, ASTM International, 100 Barr Harbor Drive, West Conshohocken, PA 19428-2959

[6] ASTM G 145, Standard Guide for Studying Fire Incidents in Oxygen Systems, ASTM International, 100 Barr Harbor Drive, West Conshohocken, PA 19428-2959

[7] ASTM Manual 36 (MNL36), Safe Use of Oxygen and Oxygen Systems: Handbook for Design, Operation, and Maintenance, ASTM International, 100 Barr Harbor Drive, West Conshohocken, PA 19428-2959

[8] CGA G-4, Oxygen, Compressed Gas Association, Inc., 4221 Walney road, $5^{\text {th }}$ Floor, Chantilly, VA 20151, email: cga@cganet.com

[9] CGA G-4.1, Cleaning Equipment for Oxygen Service, Compressed Gas Association, Inc., 4221 Walney road, $5^{\text {th }}$ Floor, Chantilly, VA 20151, email: cga@cganet.com

[10] ISO14624-1, Space Systems - Safety and Compatibility of Materials - Part 1: Determination of Upward Flammability of Materials, ISO Copyright Office, Case Postale 56, CH-1211 Geneva 20, email: copyright@iso.org

[11] ISO14624-4, Space Systems - Safety and Compatibility of Materials - Part 4: Determination of Upward Flammability of Materials in Pressurized Gaseous Oxygen or OxygenEnriched Environments, ISO Copyright Office, Case Postale 56, CH-1211 Geneva 20, email: copyright@iso.org

[12] NFPA 53, Recommended Practice on Materials, Equipment, and Systems Used in OxygenEnriched Atmospheres, NFPA, 1 Batterymarch Park, Quincy, MA 02169-7471 
[13] NASA Materials and Processes Technical Information System (MAPTIS.) This is the official NASA materials database, which houses volumes of materials data, including oxygen compatibility information and data. This database is useful to the experienced oxygen system designer, but not as much to the new designer. It can be found at http://maptis.nasa.gov

[14] NASA-STD-6001, Flammability, Offgassing, and Compatibility Requirements and Test Procedures

[15] NASA TM-213740, Guide for Oxygen Compatibility Assessments on Oxygen Components and Systems 